\title{
The Effectiveness of Mandala Colouring Therapy in Increasing Year 3 Pupils' Focus during the Initial Lesson
}

\author{
Ravi Shankar',2, Ruslin Amir² \\ ${ }^{1}$ SK (Felda) Jengka 23, Temerloh, Malaysia \\ ${ }^{2}$ Faculty of Education, Universiti Kebangsaan Malaysia (UKM), Bandar Baru Bangi, Malaysia \\ Email: ravi199322@gmail.com
}

How to cite this paper: Shankar, R., \& Amir, R. (2020). The Effectiveness of Mandala Colouring Therapy in Increasing Year 3 Pupils' Focus during the Initial Lesson. Creative Education, 11, 581-595.

https://doi.org/10.4236/ce.2020.114043

Received: March 1, 2020

Accepted: April 23, 2020

Published: April 26, 2020

Copyright (C) 2020 by author(s) and Scientific Research Publishing Inc. This work is licensed under the Creative Commons Attribution International License (CC BY 4.0).

http://creativecommons.org/licenses/by/4.0/ (c) (i) Open Access

\begin{abstract}
Focus is a very important element in the world of education to increase the effectiveness of other learning skills such as reading, writing and calculating. The lack of focus issue existed as the pupils were uninterested and unmotivated to learn. This has caused disruptive behaviours in the classroom which affected both teachers and pupils. An intervention was essential in curbing this problem. Hence, this study was embarked to identify the effectiveness of the Mandala Colouring Therapy in increasing Year 3 pupils' focus during the initial lesson of the day. A mixed method study was conducted at 5 national schools in Temerloh, Pahang. The participants were 100 Year 3 low average pupils and 20 teachers who taught initial lesson periods. The data were collected through interviews and questionnaires. The quantitative data were analysed using frequency counts on SPSS, while the qualitative data were analysed using Burnard's method. The overall findings revealed that pupils' interest and focus has been increased with Mandala Colouring Therapy. Besides, teachers have also admitted that this method has enabled the low average pupils to answer questions correctly, complete the tasks and change their behaviours. The implication of the study is that the education stakeholders need to be made aware of these impacts in order to implement this effective method in classrooms to have a fruitful teaching and learning session.
\end{abstract}

\section{Keywords}

Mandala Colouring Therapy, Focus, Year 3 Pupils, Low Average, Disruptive Behaviour

\section{Introduction}

"Learning... is a reflective activity which enables the learner to draw upon pre- 
vious experience to understand and evaluate the present, so as to shape future action and formulate new knowledge" (Watkins et al., 2002). Learning process is an integral part of an individual's life. Basic concept of learning is to produce a holistic individual in terms of being competent, developing potential, and has high moral standards. These are embodied in the goals and focus of each educational system around the world.

For instance, the importance of learning and its primary goals are stipulated in the National Education Philosophy. In Malaysia, every child is required to have primary schooling compulsorily. The curriculum developed for primary education has also stressed the importance of learning. One of the underlying pedagogical principles of KSSR curriculum is that learning should be fun, meaningful and purposeful. This is to enable the pupils to construct new knowledge via learning and also to build a strong foundation for children's learning development.

In order to succeed in the learning session, a child needs to stay focused during the teaching and learning process. To ensure that, by the end of the lesson, the pupils could achieve the learning objective for a particular lesson. However, there are few issues encountered in the classroom that prevents smooth learning session. They are namely, disruptive behaviour, lack of motivation and most importantly, lack of attention.

Abdullah (2015) stated that students' attention lapses during the initial minutes of "settling-in", again at $10-18$ minutes into the lesson. Lundervold et al. (2017) in his research stated that two of the teachers reported inattention items significantly predicted a low rather than a medium academic achievement score. Baranek (1996) stated that poor student achievement is often attributed to a lack of motivation. Lack of motivation and lack of interest has caused lack of focus issue which led to low academic achievement score and disruptive behaviour. Abdullah et al. (2016) stated that "Many individuals with learning problems are described not only as learning disabled, but also as hyperactive, distractable, impulsive, behaviour disordered, and so forth. Jacobsen (2013) in his research stated that disruptive behaviour is witnessed by elementary school teachers on a daily basis in their classroom. These disruptive behaviours will later on affect the learning achievement of the pupils. All these are mainly caused by lack of focus issue in the classroom. Hence, this issue was aimed to be resolved through the conduct of this research study.

\section{Literature Review}

A closer look into the recent literature showed that researchers have focussed on the evaluation of literacy instruction program for a variety of purposes.

Souriyavongsa et al. (2013) stated most of the students having difficulties in learning because they were not well-motivated, encouraged and gained learning strategy. Research has shown that individuals use different ways when it comes to learning a second language. The success in learning depends upon many factors such as learning style, motivation (Deci \& Ryan 1985), and attitude towards 
the subject (Walqui, 2000). Achievement in a target language as proposed by Mohamad Jafre (2012) relies not only on intellectual capacity, but also in the learners' attitudes towards language learning. Positive attitude will significantly contribute to the success of learning (Samsiah et al., 2009). Conversely, negative attitudes may lead to class anxiety (Ratnawati \& Ismail 2003), low cognitive achievement, and low motivation (Victoria \& Lockhart 1995).

Oxford Learning (2018) has stated that it is common for students at all grade levels to have trouble staying focused. Weimer (2014) stated that most students reported short lapses (a minute or less) significantly more times than the medium- or longer-length lapses. Whether it's struggling to pay attention in class or having a tough time completing homework assignments, focus issues can have a big impact on student's performance. This has affected the teaching and learning process. Bradbury (2016) has stated that, several educational organizations have decreased their teaching and learning process to $15 \mathrm{~min}$ in length based upon the "common knowledge" and "consensus" that there is a decrement in pupils' attention 10 - 15 minutes after the teaching and learning processes has taken place. Hence, keeping pupils focused in a classroom is no longer an alienated issue in a school.

Besides that, primary learners are found to be having problem in answering questions posed by the teacher. When it comes to low average pupils, Corrigan (2015) stated that one or two students attempted an answer, while the others sat quietly in their seats, avoiding eye contact with the researcher. The room filled with awkward silence: 5 seconds, 10 seconds, 20 seconds. This is one of the most important issues that must be addressed in order to provide a meaningful teaching and learning session. When a student could not answer questions given by the teacher, the learning objectives for the day will not be achieved. Since learning objectives communicate the knowledge and skills that instructors intend for students to acquire in a course, thus, it will affect both the students and teachers (Mekonnen, 2018).

In this research, the researcher has used Mandala Colouring Therapy as an intervention to curb the lack of focus issue. The use of Mandala Colouring Therapy is believed to have positive impacts. Toozhy (2016) has stated that Mandalas, especially their mid points, are utilized for meditation for a better attention and focus. Semple et al. (2017) has stated that mandala colouring helps to still the mind and focus attention. Potash et al. (2016) stated that the objective of his qqualitative research study was to discover how creating mandalas (art made in reference to a circle) might provide medical students with an opportunity for reflection on their current psychological state.

There have also been many studies showed that a mandala is an effective tool for therapeutic purposes (Kim et al., 2017). Research conducted by Mancuso et al. (2019) showed that structured coloring of Mandala pattern might induce a meditative state that benefits individuals are suffering from anxiety. The same thing was also stated Babouchkina \& Robbins (2015) who conducted experimental research which the results demonstrated that the circular shape of the 
mandala serves as an "active ingredient" in mood enhancement.

Colouring positively impacts the pupils. Rodski (2012) has used colouring therapy for relaxation and meditation. He has taken this concept from art therapy. Flett et al. (2017) who concluded that daily coloring can improve some negative psychological outcomes and that it may provide an effective, inexpensive, and highly accessible self-help tool for nonclinical samples. Eaton \& Tieber's research (2017) showed positive effects of coloring. It is found greater to be a therapy in anxiety reduction.

Hence, the researcher has used Mandala Colouring Therapy to resolve lack of focus issue which had a positive impact on the pupils.

\section{Methodology}

\section{Research design}

For this study, a mixed method research design was chosen. Mixed method research design is the type of research in which a researcher combines elements of qualitative and quantitative approaches for the broad purposes of breadth and depth of understanding and corroboration. This approach to research was used as the integration provides a better understanding of the research problem than either of each alone.

Participants

Purposive sampling was used in this study. 100 Year 3 pupils and 20 teachers were selected. The pupils were selected based on three criteria. The criteria were students of low average category in a Year 3 classroom, projected disruptive behaviour and the students who did not achieve learning objectives. The teachers who were teaching initial lessons for the Year 3 pupils, encountered disruptive behaviour and those who could not achieve the teaching objectives were selected as the participants. This study was conducted with five national schools in Temerloh District.

Data analysis

This study embraced mixed method approach and thus employed methods that are in line with the study. Both quantitative and qualitative methods were used in this research. The research instruments were teacher individual interview and questionnaire for pupils. For the quantitative approach, 5-point Likert scale was used. The number of pupils selected an option for a statement, determined if they strongly disagreed, disagreed, not sure of the response, agreed, and strongly agreed to the statement. All the data were collected, processed and analyzed using the Statistical Package for the Social Science (SPSS). The data were statistically analyzed using frequency counts and percentage distribution. The percentage distribution was computed to determine if Mandala Colouring Therapy has increased Year 3 pupils' focus during initial lessons.

For the qualitative method, individual interview was used to gather data from the teacher. As the teacher has a direct involvement with the issue studied, it was essential to analyse their view point. The questions were divided into two sections. Section A of the questions required the teacher to reflect on issues that the 
teachers have encountered while teaching. Meanwhile questions from section B focus on the changes that can be seen in pupils after the implementation of the Mandala Colouring Therapy. The data from interviews were analyzed using Burnard et al. (2008). Burnards proposed 14 stages in analysing qualitative data which is based on a synthesis between grounded and content analysis approach. This method was used to categorize and code the transcribed interview data.

\section{Results and Discussion}

The findings of this study indicated that the Mandala Colouring Therapy has increased Year 3 pupils' focus during initial lessons. Through the individual interview, it was identified that Mandala Colouring Therapy has helped the low average pupils in 1) Answering questions, 2) Task completion and 3) Behavioural changes which were also equally important and contributing effects in this case.

RQ1-What is the effectiveness of the Mandala Colouring Therapy on increasing pupils' focus during the initial lesson of the day.

This questionnaire entitled "Focus" and "Interest" was administered to all 100 participants based on two subsections. The answers are divided into two parts which answers the two subsections; 1) Focus and 2) Interest.

Focus

For the first statement, $70 \%$ have strongly agreed that they can complete all the tasks given. $20 \%$ have chosen agree. This is supported by Dzulkifli \& Mustafar (2012). They have stated that colours can play a role in motivating pupils to learn and profit from their educational experiences. It could be evident when the pupils were able to complete all the tasks given. This was only possible with the implementation of Mandala Colouring Therapy. This is supported by Semple et al. (2017). It has been proved that mandala colouring helps to still the mind and focus attention. The data from the interview was used to triangulate this data. One of the participants agreed that the pupils were able to complete the task without having to be guided. Similarly, another participant admitted that the pupils are able to finish up the task in given time. Thus, this proves the effectiveness of Mandala Colouring Therapy in increasing Year 3 pupils' focus during initial lesson of the day.

For the second statement, $10 \%$ have strongly agreed that they can complete the tasks within the time given. $80 \%$ have agreed. This is supported by Davis (2015). She stated that colouring can help a child develop his or her overall concentration levels. It is not easy to motivate them to perform school tasks (Assaid, 2003). When a child learns on how to concentrate in their teaching \& learning environment, this it helps the child to perform tasks in time given. Hence, this proves the effectiveness of Mandala Colouring Therapy in increasing Year $3 \mathrm{pu}-$ pils' focus during initial lesson of the day as the pupils could complete the tasks within the time given.

For the third statement. $35 \%$ have strongly agreed that they can answer the questions correctly. 50\% have agreed. Botros (2009) indicated that lack of focus has symptoms that appear on pupils through different situations; forget much of 
the content. So, an intervention is important is curbing this problem. Using Mandala Colouring Therapy in this research has positively impacted the pupils. Colouring can also visually guide you to locate, compare, understand and recall information faster. Hence, the pupils were able to recall the lesson taught by the teacher and answer the questions well. The data from the interview has revealed that the pupils can answer confidently. They were also seen answering correctly. This supports the questionnaire data when $50 \%$ of the participants have agreed to be able to answer correctly. Thus, this proves the effectiveness of Mandala Colouring Therapy in increasing Year 3 pupils' focus during initial lesson of the day.

For the fourth statement, $75 \%$ have strongly agreed that they can complete tasks based on teacher's instruction. $15 \%$ have agreed. In order to meet the learning objectives, the pupils should be able to complete the tasks given. This could only be possibly done if the pupils have focused on the teacher's instruction. As Maria (2012) stated that it can be concluded that the application of visual assist to draw students' attention, raise and ease understanding of the second language and to gain their motivation. Toozhy (2016) also has stated that Mandalas, especially their mid points, are utilized for meditation for a better attention and focus. Through this research, the implementation of visuals in the form of Mandala Coloring Therapy has definitely aided the pupils in focusing on the teacher's instruction as they were able to complete the tasks based on the instruction.

For the fifth statement, $70 \%$ have strongly agreed that they can complete tasks without teacher's facilitation. $10 \%$ have agreed to the statement as well. One of the underlying principles of KSSR is learning is pupils-centred (Ministry of Education, 2013). The active role pupils play in a teaching and learning session is beneficial as it produces pupils with high competence. The implementation of Mandala Colouring Therapy in this research has played a vital role in enabling the pupils to stay focussed in the classroom which directly leads them to complete the tasks given without having to wait for facilitation from the teacher. Therefore, this is considered as one potential strategy to mitigate the negative effects of boredom in classroom (Belton \& Priyadharshini, 2007).

\section{Interest}

For the first statement, it is seen that 20 pupils with the rate of $20 \%$ have strongly agreed and 60 pupils with the rate of $60 \%$ agreed that they actively participate during the lesson. Active participation is very important during the teaching and learning session. It is also highlighted in the National Education Blueprint (NEB) in achieving one of the six key attributes, which is Knowledge (Ministry of Education, 2013). This is also supported by Susan (2018). She has stated that providing opportunities for them to colour helps with that and the noise level is generally pretty quiet even though they are talking with their neighbour.

For the second statement, $27 \%$ have strongly agreed and 59\% agreed to the statement. An active question and answering session are important as it indi- 
rectly supports the implementation of pupils-centered learning, which is a key principle of our education policy (Ministry of Education, 2013). Answering questions given by the teacher also determines whether the pupils have been focusing on the lesson. For the third statement, we could see that $55 \%$ have strongly agreed to the statement. 30 pupils with the rate of $30 \%$ have agreed to the statement. If pupils are interested in a lesson, they will look forward to attend the class. Previously, the pupils were seen bored. However, with the help of Mandala Colouring Therapy, pupils now look forward to the lesson as they are interested in learning session. This has also increased their extrinsic motivation to learn, which leads to extra focus on the subject key taught. Mulvahil (2018) stated that extrinsic motivation is extremely beneficial, particularly in situations where pupils need to complete a task that they find unpleasant.

For the fourth statement, $60 \%$ have strongly agreed to the statement and $25 \%$ have agreed to the statement. Enjoying a lesson is an important impact of an effective teaching and learning session. This could be possibly done if the pupils stay focused in the classroom and avoided boredom. Pekrun et al. (2011) found that boredom was negatively related to motivation to learn, processing of information, and memory. Thus, a stimulus that triggers the brain is important to be integrated, which is colour. According to Wellesley College (2013), colour is one of the important stimuli to our brain. Pupils can learn better when they have introduced to colour. This stimulus triggers thinking process which requires them to focus in the classroom and enables the pupils to learn better.

For the fifth statement, we could see that $15 \%$ have strongly agreed to the statement and 70 pupils with the rate of $70 \%$ have agreed to the statement. Majority of the pupils agreed that they were not only able to finish their tasks, but, at thue same time, they can also guide their friends to finish off their tasks as well. It is affirmed that; the pupils will only learn or help their friends in that specific subject if they have interest on it. Kishore (2003) said "visual aids stimulated thinking and cognize". This implies that the visuals aid the pupils in increasing their interest. This is supported by Harackiewicz (2016). They have stated that interest is often thought of as a process that contributes to learning and achievement. That is, being interested in a topic is a mental resource that enhances learning, which then leads to better performance and achievement.

In short, it can be said that the Mandala Colouring Therapy is effective in helping the participants to be interested and stay focused during the initial lesson of the day. Webb (2017) stated that if you were looking for evidence of learning in any classroom, you would likely start by looking for general observations of gains in knowledge, understanding, skills and attitudes. In the classroom, it can be seen through how the pupils finish up the tasks, how they behave and on how long do they take to complete the tasks given by the teacher. Compared to the previous lesson, now, the pupils are paying attention and focussing during the initial lesson. The pupils were seen motivated and interested during the initial lesson. Hence, it was proven that the Mandala Colouring Therapy is effective in increasing Year 3 pupils' focus during the initial lesson of the day. 
What is the teacher's perception on Mandala Colouring Therapy in increasing Year 3 pupils' focus during the initial lesson of the day?

This interview was administered to all 20 participants. All of the participants have been teaching initial lessons for the Year 3 pupils, encountered disruptive behaviour and could not achieve the teaching objectives. The answers for the open-ended questions were divided into Section A, Section B and three parts which answers the three themes: 1) Answering Questions, 2) Task Completion, and 3) Behavioural changes.

\section{Section $A$}

For Section A, most of the participants were expressing that the pupils had issues during the initial lesson of the day. Geschler (2012) stated that the concept of attention span is of utmost importance in the classroom, where a failure to focus can have disastrous results. Therefore, the pupils have to stay focused and pay attention during the lesson so that they can catch up with the classroom progress and not being left out. However, the participants have agreed that they encountered few issues when it comes to the lesson during the initial lesson of the day. The issues were playing around, talking and disturbing their friends, sleeping and not listening to the teachers' instruction. As a whole, these can be classified as the disruptive behaviours. The disruptive behaviour expressed by the teachers can affect the pupils' focus and have a great negative impact on learning achievement in their classroom activities and exams. This disruptive behaviour has definitely been a great challenge for the teachers as they have to come up with an intervention that could be effective in making the pupils stay focussed in the classroom. This is supported by Douglas (2016), were it has been stated that disruptive behaviour by pupils is a problem that should be challenged and managed effectively from the beginning of a pupils' study.

The participants were expressing the reasons for the issues to happen in the classroom. The participants have agreed to few main reasons for the issues to happen during the initial lesson of the day. The teachers have pointed out few reasons for the issues to present in the classroom. One of the issues is lack of interest in the lesson. When there's no interest, it automatically causes disruptive behaviour and lack of focus. Geschler (2012) stated that the ability of a pupil to focus during class is partially a result of the pupils's interest. Besides, lack of motivation also caused this issue. Saaed \& Zyngier (2012) have stated that motivation is seen as a pre-requisite of and a necessary element for pupils' engagement in learning. So, motivation is also an important factor in the learning session as it enables the pupils to actively engage in the lesson. Pupils' involvement in learning should not be let unnoticed because then it will affect pupils from achieving sound academic outcomes. These were the reasons why the pupils were lack of focus in the classroom activities.

\section{Section $B$}

For the first question of Section B, most of the participants answered yes. They could see positive changes among the pupils during the initial lesson of the day after implementing the Mandala Colouring Therapy. Some of them stated 
that the pupils can remember better the topics taught during the initial lesson and it results in positive academic achievements. The Mandala Colouring Therapy did help the pupils to act positively during the lesson. According to Spence et al. (2006), if colour can increase arousal, and arousal can increase memory, then it is possible to assume that we could find that colour can increase memory. Hence, if the pupils could get better during colouring, then they can focus ad remember the input that they received during the lesson, which subsequently results in the positive academic achievement and in teaching and learning session objective achievement.

\section{Answering Questions}

The first theme derived from the participant's response was answering questions. This theme refers to the willingness of the pupils to answer questions confidently. Pupils should be able to answer questions correctly in order to convince the teachers that they have paid full attention during the classroom. Hakala (2015) stated that deep processing, resulting from engaged pupils, leads to better learning. Hence, when the pupils could answer questions, given by the teacher correctly, it can be evident that the pupils were paying attention to the lesson.

Answering questions asked by the teacher is indeed a positive change that can be easily noticed by the teacher. It shows that the pupils were paying attention during the lesson. McClure (2010) stated that pupils perceive their role in learning is to listen for shared knowledge by their instructor and then memorize and present those answers to assess their understandings. From the excerpts above, it can be seen that the pupils did listen to the teacher to answer questions that will be asked in the class. This was only possible with the implementation of Mandala Colouring Therapy which increased pupils' focus during the initial lesson of the day.

\section{Task Completion}

The second theme derived from the participants' interview response was task completion. Task completion refers on how the pupils could complete the tasks given by the teacher correctly without having to be assisted by the teacher. The pupils also were able to complete the task in specific time given. Most of the tasks given by the teacher were answered correctly by the pupils. It is important to get good answers rather than just getting tasks done in the specific time given. Being able to complete the task given by the teacher is one of the positive indications showed by the pupils that they understand the lesson taught by the teacher. Gunn (2017) stated that when a pupil can explain their learning and the why of it, that's a total win. Hence, if the pupils were able to complete the task and explain their answer, it can be concluded that the pupils clearly understood the lesson as they were focusing on the lesson. Hence, this proves the effectiveness of Mandala Colouring Therapy in increasing Year 3 pupils' focus during the initial lesson of the day.

\section{Behavioural Changes}

The third theme derived from the participants' interview response was behavioural changes. Change of behaviour can easily be noticed if a pupil pays atten- 
tion and motivated to learn during a lesson. Teachers should play a vital role in noticing negative behaviour in the classroom that indicates whether the pupils engaged or not in a classroom. Udin (2013) stated that educator should select effective teaching and learning approach to instil sustainability on pupils' knowledge and behavioural changes in practicing sustainable lifestyles. Positive behavioural changes that have been noticed by the teacher show that pupils are paying attention and motivated during the lesson. Positive behaviour in a classroom promotes better learning. Weber et al. (2016) suggested school-related positive affect as a mediator between certain affect-favoring character strengths (zest, perseverance, love of learning, social intelligence), positive school functioning, and school achievement. Hence, if the pupils promote good behaviour, it can result in good academic achievement. If the pupils are paying attention and motivated to learn, it will help the pupils to understand the lesson better as well as improves their academic achievement.

Besides focus and interest, answering questions, task completion and behavioural changes were also the other contributing impacts of the effectiveness of Mandala Colouring Therapy in increasing the Year 3 pupils' focus during initial lesson of the day. Thus, this section identified the contributing positive impacts which answer the research question and that it is important to be considered by the Ministry of Education in curbing this problem.

\section{Implication}

Malaysian Education system aimed to produce pupils who are developed holistically and acquire all skills to be globally competent. This is in line with the National Education Philosophy and the New Education Blueprint (2013-2025). In order to be globally competitive, one has to master the academics and the other skills. The achievement in academics is relied on the teaching and learning process. However, the success rate of a teaching and learning process largely depends on the focus level of the pupils. In order to have a better academic achievement, the learners need to stay focused and actively participate during the lesson in the classroom.

The Ministry of Education has taken up numerous measures in ensuring the smooth progress of teaching and learning process. However, there were many issues raised in the primary classroom involving disruptive behavior, lack of focus, interest and motivation during the lesson. These happened extremely during initial lessons. Hence, this research was embarked to identify the possible method to overcome the issues faced by the learners which affect the daily teaching and learning session. The findings of the research will greatly benefit the learners as the learners now will be able to utilize much impactful method, Mandala Colouring Therapy to help them stay interested and focused during the lesson.

In addition, this research has also identified learner factors that contributed to the lack of focus issue. They were namely, lack of interest, motivation and dis- 
ruptive behaviour. These are considered to be a challenge during teaching and learning session. This is important in making the pupils to understand their role in achieving the learning objective. Even though, the participants of this study are still lower standard pupils, yet, they still need to be explained on the importance of playing an active role in achieving the learning objectives and how this in turn will be helpful for them in the future. Through this research, the pupils will be greatly benefitted as they will be able to avoid any issues, with the help of Mandala Clouring Therapy that prevents them from having a smooth learning session.

New Education Blueprint (2013) expects the teachers to produce pupils who are proficient and globally competitive. It has also been implementing new plans and programs, with teachers being the implementers, hoping that the percentage of minimum score achievers will be increased. To a noteworthy extent, teachers' role in realizing the Ministry's goals is huge.

Hence, this research was a great benefit for the teachers in terms of classroom management. Classroom management has always been a hot topic to be discussed among the teachers. Each and every one will be facing different struggles in terms of classroom management. The teachers now do not have to waste their time to make the class under control before beginning the initial lesson of the day. The teachers can have better classroom management with the aid of Mandala Colouring Therapy. The teacher could calmly deliver the lesson without any interruption that could affect the teaching and learning process. This also can help in achieving the teaching and learning session's objective.

Besides, this research has also made positive changes in the learners in terms of behavior. It is well known that the "Bimbingan dan Kaunseling" unit in school will be planning programs every year to shape pupils' character. This would cost a whopping amount. However, through this research, an effective method is proven to positively change the behavior of the pupils and it is cost-effective. Similarly, the core subjects' panels will be planning programs to improve the learning achievement of the pupils. Since this research has improved the behavior and the learning achievement of the learners, this will be a great benefit for the teachers, as they can implement a cost-effective method to witness a fruitful impact.

One of the most important education stakeholders is the Ministry of Education. The ministry has always been coming up with plans and programs to be implemented in the local classrooms in bringing up the positive outcome. However, whenever a plan fails, the teachers are to be blamed. Hence, this research acts as an eye opener for the Ministry of Education that there are other factors to be considered when a plan fails. This is because, this research has identified learner factors which contribute to the failure of a teaching and learning session, which was mainly caused by lack of focus, motivation, interest and disruptive behaviour.

Secondly, by implementing this therapy, the pupils will be more focused and motivated to learn which results in achieving the intended goals of the Ministry. 
Indirectly, it helps the pupils to achieve the six key attributes which has been laid out in the Malaysia Education Blueprint, especially Knowledge. This has also paved way for Ministry of Education in realizing the National Educational Philosophy's goal which is to produce holistic, competent and sensible citizens.

Through this research, the Ministry of Education will also be aware of the importance of Mandala Colouring Therapy and will be convinced to support the integration of arts in school. Producing a holistic individual is not always about excellent academic achievement, but balanced physical and mental health. As Mandala Colouring Therapy, a form of art, is proven to be reducing stress, disruptive behaviours and increase positive outcomes, it is necessary for the Ministry of Education to emphasize the importance of integrating art education.

\section{Recommendation}

The following are some suggestions that researchers might want to consider for future research. First, this study can be explored further by focusing on the core subjects of national schools. Core subjects are being tested in Ujian Pencapaian Sekolah Rendah (UPSR) at national level and its achievement is important for the learners for their secondary schooling. Hence, for future research, this research can be focused on the effectiveness of Mandala Colouring Therapy for Bahasa Malaysia, Bahasa Inggeris, Mathematics and Science subjects and in enhancing pupils' achievement. It could have a great impact on the pupils' achievement in PPSR as it can be so effective for Year 3 pupils.

Secondly, for further research, multiple researches can be carried out to compare the outcomes of the findings. For example, this Mandala Colouring Therapy can be implemented in vernacular schools as this research only focused in national schools. Vernacular schools in Malaysia are Chinese schools and Tamil schools. Apart from that, this could also be carried out in homogenous schools. Since this research was only focused for Year 3 pupils of national schools, the results could not be generalized. Hence, by conducting this research in vernacular schools as well, the validity of effectiveness can be tested in greater details and in larger scale.

Following that, this research could also be conducted during the last lesson of the day to compare the outcomes. It is a known fact that, classroom usually will be out of control during the initial and last lesson period of the day. This research can be further explored by implementing it during the end of the day subjects. In this way, the effectiveness of Mandala Colouring Therapy can be tested in a more detailed manner.

Finally, this study could also be expanded on areas of suggestions for improvisation. This research has only focused in increasing the focus using Mandala Colouring Therapy where it has explored the contributing learner factors regarding the issue. However, it has not explored the teacher factors which cause the issues in the classroom. This will enable the teachers to reflect of their instructional practices and improve them. 


\section{Conclusion}

This research was conducted to investigate the effectiveness of the Mandala Colouring Therapy in increasing Year 3 pupils' focus during the initial lesson of the day. The findings of the study indicated that Mandala Colouring Therapy has increased Year 3 pupils' focus and interest. The teachers too shared the other positive impacts they identified while implementing.

Mandala Colouring Therapy benefits were the low average pupils that can answer questions, complete tasks and have positive and a non-disruptive behaviour. Mandala Colouring Therapy had also benefitted the teachers in terms of classroom management, where no disruptive behaviour was evident and in terms of achieving teaching and learning objectives through task completion and answering questions during lesson. These could be clearly seen based on the data collected through questionnaire and interview protocol.

In this revolutionized world, the success of an individual largely depends on the academic achievement, behaviour and skills. This could only be achieved through full attention during the lesson. Therefore, it is important to integrate this Mandala Colouring Therapy as it has assured a fruitful impact and benefitted education stakeholders by enabling pupils to be focussed on the lesson.

\section{Conflicts of Interest}

The authors declare no conflicts of interest regarding the publication of this paper.

\section{References}

Abdullah, H. (2015). A Case Study on Visual Spatial Skills and Level of Geometric Thinking in Learning 3D Geometry among High Achievers. Journal Man in India, 95, 489-499.

Abdullah, H., Mohd Asraf, R., Zamin, A. A., \& Zamin, M. (2016). Literacy among Malaysian Primary Schoolers: How Do Boys Perform Relative to Girls? International Electronic Journal of Elementary Education, 9, 225-238.

Assaid, A. (2003). Learning Difficulties its History, Nature, Diagnosis, and Treatment. Cairo: Al-Fiker Al-Arabi.

Babouchkina, A., \& Robbins, S. J. (2015). Reducing Negative Mood through Mandala Creation: A Randomized Controlled Trial. Journal of The American Art Therapy Association, 32, 34-39. https://doi.org/10.1080/07421656.2015.994428

Baranek, L. K. (1996). The Effect of Rewards and Motivation on Student Achievement. https://scholarworks.gvsu.edu/cgi/viewcontent.cgi? article=1292\&context=theses

Belton, T., \& Priyadarshini, G. (2007). Boredom in School and It's Effect on Your Child's Health.

https://www.huffpost.com/entry/boredom-in-school-and-its_b_200602

Botros, H. (2009). Teaching Learning Difficulties Students (1st ed.). Amman: Al-Maseerah Publishers.

Burnard, P., Gill, P., Stewart, K., Treasure, E., \& Chadwick, B. (2008). Analysing and Presenting Qualitative Data. British Dental Journal, 204, 429-432.

https://doi.org/10.1038/sj.bdj.2008.292 
Corrigan, P. (2015). Why Students Don't Answer a Question, What Does The Awkward Silence Mean?

https://teachingandlearninginhighered.org/2015/05/28/when-students-dont-answer-aquestion-what-does-the-awkward-silence-mean/

Davis, J. (2015). Benefits of Colouring in Activities. https://www.learning4kids.net/2015/06/22/benefits-of-colouring-in-activities/

Deci, E. L., \& Ryan, R. M. (1985). Intrinsic Motivation and Self-Determination in Human Behavior. New York: Plenum.

Douglas, D. et al. (2016). The Impact of Disruptive Behavior in the Classroom: The Student Perspective.

Dzulkifli, M, A., \& Mustafar, F. M. (2012). The Influence of Colour on Memory Performance: A Review. The Malaysian Journal of Medical Sciences, 20, 3-9.

Eaton, J., \& Tieber, C. (2017). The Effects of Coloring on Anxiety, Mood, and Perseverance. Journal of The American Art Therapy Association, 34, 42-46. https://doi.org/10.1080/07421656.2016.1277113

Flett, J. A. M. et al. (2017). Sharpen Your Pencils: Preliminary Evidence that Adult Coloring Reduces Depressive Symptoms and Anxiety. Creativity Research Journal, 29, 409-416. https://doi.org/10.1080/10400419.2017.1376505

Geschler, J. (2012). Classroom Strategies For Maintaining Student Focus.

Gunn, J. (2017). How Do We Actually Know a Lesson Went Well. https://education.cu-portland.edu/blog/classroom-resources/how-do-we-actually-kno w-a-lesson-went-well/

Hakala, C. (2015). Why Cant Students Just Pay Attention. https://www.facultyfocus.com/articles/effective-teaching-strategies/why-cant- students-just-pay-attention/

Harackiewicz, J. M., Smith, J. L., \& Priniski, S. J. (2016). Interest Matters: The Importance of Promoting Interest in Education. Policy Insights from The Behavioral and Brain Sciences, 3, 220-227. https://doi.org/10.1177/2372732216655542

Jacobsen, K. (2013). Educators' Experiences with Disruptive Behavior in the Classroom. https://sophia.stkate.edu/cgi/viewcontent.cgi?article=1201\&context=msw_papers

Jafre, M. et al. (2012). EFL Students' Attitudes towards Learning English Language: The Case of Libyan Secondary School Students. https://www.semanticscholar.org/paper/EFL-Students'-Attitudes-towards-Learning-En glish-of-Abidin Pourmohammadi/ad450b6d21cbacc2853b31df4f296c0bb7d787f2

Kim, S, I. (2017). Computational Art Therapy. New York: Charles Thomas Publisher.

Kishore, N. (2003). Impact of Visual Aids in Enhancing the Learning Process. https://files.eric.ed.gov/fulltext/EJ1079541.pdf

Lundervold, A. J., Bøe, T., \& Lundervold, A. (2017). Inattention in Primary School Is Not Good for Your Future School Achievement-A Pattern Classification Study. PLoS ONE, 12, e0188310. https://doi.org/10.1371/journal.pone.0188310

Mancuso, E. et al. (2019). The Effectiveness of Structured Coloring Activities for Anxiety Reduction. Journal of The American Art Therapy Association, 35, 195-201. https://doi.org/10.1080/07421656.2018.1540823

Mekonnen, B. (2018). How Undergraduate Science Students Use Learning Objectives to Study. Journal of Microbiology \& Biology Education, 19, 1510. https://doi.org/10.1128/jmbe.v19i2.1510

Ministry of Education (2013). New Education Blueprint. Kuala Lumpur: Ministry of Education. 
Mulvahil, E. (2018). Understanding Intrinsic vs. Extrinsic Motivation in the Classroom. https://www.weareteachers.com/understanding-intrinsic-vs-extrinsic-motivation-in-th e-classroom/

Pekrun, R., Goetz, T., Frenzel, A. C., Barchfeld, P., \& Perry, R. (2011). Measuring Emotions in Students' Learning and Performance: The Achievement Emotions Questionnaire (AEQ). Contemporary Educational Psychology, 36, 36-48.

Potash, J. S., Chen, J. Y., \& Tsang, J. P. Y. (2016). Medical Student Mandala Making for Holistic Well-Being. US National Library of Medicine National Institutes of Health, 42, 17-25. https://doi.org/10.1136/medhum-2015-010717

Ratnawati, M. A., \& Ismail, S. A. (2003). Promoting English Language Development and the Reading Habit Among Students in Rural Schools Through the Guided Extensive Reading Program. Reading in a Foreign Language, 15, 83-102.

Rodski, S. (2012). Anti Stress, Colouring Book for Adults. http://www.colourtation.com/brainscience

Samsiah, B. et al. (2009). Motivation and Attitude in Learning English among UiTM Students in the Northern Region of Malaysia.

https://www.researchgate.net/publication/42386337_Motivation_and_Attitude_in_Lea rning_English_among_UiTM_Students_in_the_Northern_Region_of_Malaysia/citatio $\underline{\text { n/download }}$

Semple, S. J. et al. (2017). Mindfulness Goes to School: Things Learned (So Far) from Research and Real-World Experiences. Journal in Psychology in The Schools, 54, 29-52. https://doi.org/10.1002/pits.21981

Spence, I., Wong, P., Rusan, M., \& Rastegar, N. (2006). The Interactive Effects of Colors on Visual Attention and Working Memory: In Case of Images of Tourist Attractions. https://scholarworks.umass.edu/cgi/viewcontent.cgi?article=1487\&context=refereed

Souriyavongsa, T., Rany, S., Mohamad Jafre, Z. A., \& Leong, L. M. (2013). Factors Causes Students Low English Language Learning: A Case Study in the National University of Laos. International Journal of English Language Education, 1, 179-192. https://doi.org/10.5296/ijele.v1i1.3100

Susan, C. (2018). 6 Things to Know about Introverts in the Classroom. https://tophat.com/blog/susan-cain-classroom-introverts-webinar/

Toozhy, M. (2016). Improve Attention and Reduce Your Stress by Mandala. https://mehditoozhy.com/improve-your-attention-and-reduce-your-stress-by-mandala I

Victoria, M., \& Lockhart, W. (1995). Enhancing Metacognition in Self-Directed Language Learning. System, 23, 223-234. https://doi.org/10.1016/0346-251X(95)00010-H

Walqui, A. (2000). Secondary Teacher Attitudes toward including English-Language Learners in Mainstream Classrooms. The Journal of Education Research, 99, 131-142. https://doi.org/10.3200/JOER.99.3.131-143

Watkins, C., Carnell, E., Lodge, C., Wagner, P., \& Whalley, C. (2002). Effective Learning. London: University of London Institute of Education.

Webb, H. (2017). How Do You Know Your Students Are Learning (pp. 18-19)? https://doi.org/10.12968/sece.2017.7.8a

Weber, M. et al. (2016). Positive Feelings at School: On the Relationships between Students' Character Strengths, School-Related Affect, and School Functioning. Journal of Happiness Studies, 17, 341-355. https://doi.org/10.1007/s10902-014-9597-1

Weimer, M. (2014). Students and Attention: An Interesting Analysis.

Wellesley College (2013). Study Reveals Insight into How Brain Processes Shape, Color. Science Daily. https://www.sciencedaily.com/releases/2013/12/131219102759.htm 